ferritin $(\mathrm{SF})$, hemoglobin $(\mathrm{Hb})$ and hemoglobin content in reticulocytes (CHr). We measured C-reactive protein (CRP) to identify infections. Parents filled in a questionnaire to identify risk factors for ID. Results Until now we included 350 healthy infants. Forty infants were excluded (CRP $>5 \mathrm{mg} / \mathrm{l})$. ID $(\mathrm{SF}<12 \mu \mathrm{g} / \mathrm{l})$ and IDA $(\mathrm{SF}<12$ $\mu \mathrm{g} / \mathrm{l}$ and $\mathrm{Hb}<6.8 \mathrm{mmol} / \mathrm{l}$ ) were detected in 60 (19.4\%) and 27 (8.7\%) of the 310 remaining infants respectively. CHr was measured in 249 infants. 32 of $249(12.9 \%)$ infants showed iron deficient erythropoiesis $(\mathrm{CHr}<26 \mathrm{pg})$. Iron intake and use of iron fortified formula were associated with less ID ( $\mathrm{p}=0.02$ and $\mathrm{p}=0.01)$. Intake of $>500 \mathrm{ml}$ cow's milk/day was negatively associated with iron status ( $\mathrm{p}=0.01)$.

Conclusion ID is present in $19.4 \%$ of healthy young infants aged 0.5 to 3 years in the Netherlands.

Iron status was positively associated with iron intake and the use of iron fortified formula and negatively associated with excessive intake of cow's milk.

\section{SCHOOL-BASED OBESITY AND RELATED CARDIOVASCULAR DISEASE PREVENTION INTERVENTIONS IMPROVE WEIGHT AND ACADEMIC PERFORMANCE OVER A THREE-YEAR STUDY}

doi:10.1136/archdischild-2012-302724.0363

${ }^{1} \mathrm{D}$ Hollar, ${ }^{2} \mathrm{G}$ Lopez-Mitnik, ${ }^{3} \mathrm{~L}$ Hollar, ${ }^{2} \mathrm{~S}$ Messiah. ${ }^{1}$ Mississippi Food Network/University of Miami Miller School of Medicine; ${ }^{2}$ University of Miami Miller School of Medicine, Miami; ${ }^{3}$ Nova Southeastern University College of Osteopathic Medicine, Fort Lauderdale, FL, USA

Background Childhood obesity and related health consequences continue to be major clinical and public health issues in the US and abroad. Healthier Options for Public Schoolchildren (HOPS) was a school-based obesity prevention intervention with nutrition and physical activity components implemented in the elementary school setting and targeting 6-12 year olds.

Methods HOPS was implemented in August, 2004 through December 2009, and included approximately 3,200 children (48\% Hispanic) attending four elementary schools in Florida. Demographic, anthropometric (height, weight, body mass index [BMI]) and academic (Florida Comprehensive Assessment Test [FCAT]) were collected during the school year. Interventions included modified dietary offerings, nutrition and lifestyle educational curricula, school gardens, and other school-based wellness projects.

Results Repeated measures analysis showed over a three year study period the intervention $Z$ weight scores decreased significantly among boys $(0.81$ to $0.71, \mathrm{P}<0.001)$ with a trend among girls ( 0.56 to $0.51, \mathrm{P}<0.07)$. Within ethnicity, a significant decrease in $\mathrm{Z}$ weight score for Hispanics $(0.66$ to $0.59 \mathrm{P}<0.01)$ and whites $(0.62$ to $0.54, \mathrm{p}<0.02)$ was shown. Over the same time period, FCAT math scores improved significantly among girls (308 to 319, $\mathrm{p}<0.001)$ and reading scores improved significantly among boys (299 to 307 , $\mathrm{P}<0.01)$. Within ethnicity, Hispanics significantly improved both FCAT math (298 to 309, $\mathrm{p}<0.001)$ and reading (286 to 301, $\mathrm{p}<0.0001$ ) scores.

Conclusions School-based obesity prevention interventions including nutrition and physical activity components show promise in improving health and academic performance in elementary-aged children longitudinally, especially among Hispanics.

\section{CESAREAN SECTION IS ASSOCIATED WITH BODY MASS INDEX IN CHILDHOOD IN TWO BRAZILIAN BIRTH COHORT STUDIES}

doi:10.1136/archdischild-2012-302724.0364

'MZ Goldani, ${ }^{2} \mathrm{H}$ Bettiol, ${ }^{2} \mathrm{MR}$ Gutierrez, ${ }^{2} \mathrm{VC}$ Cardoso, ${ }^{3} \mathrm{MA}$ Barbieri, ${ }^{4} \mathrm{MR}$ Barbieri, ${ }^{5} \mathrm{AAM}$ da Silva, 'HAS Goldani. 'Pediatria, Hospital de Clinicas de Porto Alegre, Porto Alegre;
${ }^{2}$ Pediatria e Puericultura; ${ }^{3 P u e r i c u l t u r a ~ e ~ P e d i a t r i a, ~ U n i v e r s i d a d e ~ d e ~ S a ̃ o ~ P a u l o, ~ R i b e i r a ̃ o ~}$ Preto; ${ }^{4}$ Pediatria, Universidade Federal do Rio Grande do Sul, Porto Alegre; ${ }^{5}$ Saúde Coletiva, Universidade Federal do Maranhão, São Luis, Brazil

Background A significant association was found between cesarean section (CS) and obesity at adulthood in our previous study.

Objective To assess the association between CS and obesity in schoolchildren.

Methods We carried out two birth cohorts in Brazil: in Ribeirao Preto (RP) in 1994 and in São Luís (SL) in 1997. 2846 pairs of mothers-newborns were evaluated in RP and 2542 pairs in SL. Birth length and weight and variables were collected after delivery: gender, gestational age, type of delivery, maternal schooling and smok ing. In 2004/2005 a random sample were reassessed with anthropometric measurements: 790 children aged $10-11$ years in RP and 673 children aged 7-9 years in SL. The outcomes were BMI in Z score and obesity $\left(>95^{\text {th }}\right.$ percentile per age). A logistic model was used to investigate the association between CS and obesity. A multiple regression model was applied to investigate the association between CS and BMI.

Results Obesity rate was $13 \%$ in RP and $2.0 \%$ in SL. In the logistic regression, the association between CS and obesity remained significant after adjustment only in RP [1.72 (CI95\% 1.01-2.92)]. The linear coefficient after adjustment the association were $0.31(95 \% \mathrm{CI}$ $0.11-0.51)$ in SL and 0.25 (95\%CI 0.05-0.46) in RP.

Conclusion Cesarean section was associated to increased BMI in both cities, as previously found in adults. CS remained associated with obesity only in RP. We reinforce the previous hypothesis that intestinal flora related to type of delivery may play a role in the epidemic of obesity worldwide.

\section{MATERNAL PERCEPTION OF CHILD BODY MASS INDEX (BMI) AND CONCERNS RAISED BY HEALTH PROFESSIONALS}

doi:10.1136/archdischild-2012-302724.0365

1,2SC Tough, 'SW McDonald, 1,3M Vekved, "'K Benzies, 'M Hicks, ${ }^{3} \mathrm{~J}$ Siever. 'Paediatrics; ${ }^{2}$ Community Health Sciences, University of Calgary; ${ }^{3}$ Public Health Innovation and Decision Support, Alberta Health Services; ${ }^{4}$ Nursing, University of Calgary, Calgary, AB, Canada

Background and Aims To describe maternal perceptions of their child's BMI and maternal report of concerns about body weight raised by a health professional.

Methods Data collection took place in 2010 when children were between 6 and 8 years of age and questionnaires were mailed to 706 mothers who were part of a longitudinal cohort that had been followed since pregnancy. Mothers reported the child's anthropometric measures, and BMI was categorized as underweight, healthy, overweight, or obese based on the child's age and sex according to the World Health Organization Growth Charts adapted for Canada.

Results 450 participants completed the questionnaire (response rate $64 \%$ ). $74 \%$ of children had a healthy BMI, $10 \%$ were underweight, $9 \%$ were overweight, and $7 \%$ were obese. $80 \%$ of parents whose child was underweight believed their child was about the right weight and only $13 \%$ recalled a health professional recently raising concerns about their child being underweight. $89 \%$ of parents whose child was overweight believed their child was about the right weight and only $6 \%$ recalled a health professional recently raising concerns about their child being overweight. $62 \%$ of parents whose children were obese believed their child was about the right weight and only $18 \%$ recalled a health professional recently raising concerns about their child being overweight.

Conclusions The majority of parents whose children were not a healthy BMI misclassified their child's weight status, suggesting that there are opportunities for health professionals to educate parents about healthy BMI for their child's age and sex. 